\title{
Adrenal ultrasound
}

\author{
Diana Loreta PAUN ${ }^{1,2}$, Mara CARSOTE ${ }^{1,2}$, Ana VALEA ${ }^{3,4}$, \\ Ancuta Augustina GHEORGHISAN-GALATEANU ${ }^{1,2}$, Rucsandra DANCIULESCU-MIULESCU ${ }^{1,5}$, \\ Adina GHEMIGIAN ${ }^{1,2}$ \\ ${ }^{1}$ Department of Gynaecology, "Carol Davila" University of Medicine and \\ Pharmacy, Bucharest, Romania \\ 2"Constantin Ion Parhon" National Institute of Endocrinology, \\ Bucharest, Romania \\ ${ }^{3}$ Department of Endocrinology, "Iuliu Hatieganu“ University of Medicine and \\ Pharmacy, Cluj-Napoca, Romania \\ ${ }^{4}$ Department of Endocrinology, Clinical County Hospital, Cluj-Napoca, Romania \\ 5"Nicolae Paulescu“ National Institute, Bucharest, Romania
}

\begin{abstract}
Ultrasound is the first step to detect an abdominal tumour at the level of adrenal. The most common scenario is related to the pelvic and abdominal ultrasound. This kind of tumour is more frequently seen in menopausal women than in premenopausal ones. We introduce a case of a menopausal woman accidentally detected at ultrasound with an adrenal mass starting from a routine gynaecological control. The use of ultrasound on adrenal masses is related to their detection and follow-up in cases when surgery is not necessary.
\end{abstract}

Keywords: adrenal, ultrasound, tumour

\section{INTRODUCTION}

Adrenal tumours especially those with lack of specific symptoms and signs have an age dependent pattern of incidence and they are commonly known as adrenal incidentaloma $[1,2,3]$. While radiological term means only an incidentally detected mass, the endocrinologists usually use the term for confirmed non-secretor tumours with an accidental detection $[1,2,3]$. The most common scenario of detection is related to the initial use of pelvic and abdominal ultrasound $[1,2,3]$. The gynaecological endocrinology link involves the fact that this kind of tumour is more frequently seen in menopausal women than in premenopausal ones $[4,5,6]$. Despite that the very essence of the condition includes asymptomatic frame, some non-spe- cific accuses as mild pain or discomfort at the level of pelvis and abdomen might be the clue to perform an ultrasound and thus to detect such tumours $[7,8]$.

\section{AIM}

We introduce a case of a menopausal woman accidentally detected at ultrasound with an adrenal mass starting from a routine gynaecological control.

\section{METHOD}

This is a case report. The ultrasound, computed tomography and endocrine features are intro- 
duced. The patient agreed for anonymously use of her medical records.

\section{CASE PRESENTATION}

This is a 65-year old female, with irrelevant family medical history, who was admitted for an adrenal tumour accidentally detected at ultrasound after an initial gynaecological evaluation. She is known with arterial hypertension under medication with controlled values of blood pressure; also she has statine therapy for hyperlipemia. She received the diagnosis of osteoporosis and multiple artrosis a few years ago but no particular therapy was offered to the patient. She had 2 births, and reached menopause at age of 50 years. An abdominal ultrasound performed in December 2016 (3 years prior to current presentation) found no particular aspect (Fig. 1).

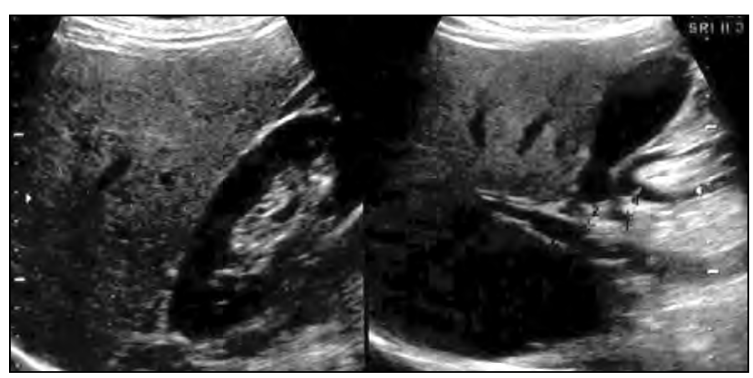

FIGURE 1. Abdominal ultrasound performed at age of 62 years did not detect any adrenal mass

\section{Admission}

Currently the patient had non-specific pain of low intensity at the pelvic and abdominal level with lumbar irradiation. A gynaecological checkup was within normal parameters for age. A pelvic and abdominal ultrasound was recommended. The patient had the echographic evaluation done and an adrenal mass at the left gland was suspected (Fig. 2).

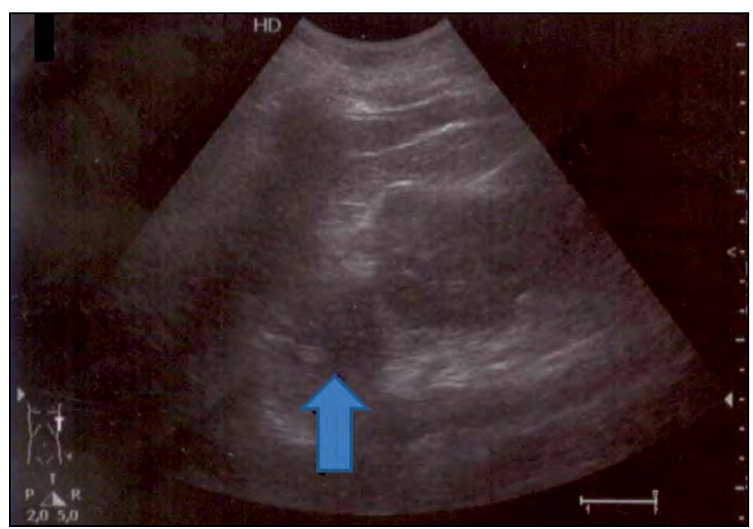

FIGURE 2. Abdominal ultrasound performed at age of 65 years did not detect any adrenal mass
The maximum diameter of the tumour is 2 centimetres $(\mathrm{cm})$. No local lymph nodes enlargement was detected. Clinical examination showed normal thyroid, and controlled cardiovascular parameters under medication.

\section{Lab findings}

Blood ionogram including serum sodium and potassium were within normal values. Oral glucose tolerance test identified impaired glucose tolerance based on a blood glucose level of $141 \mathrm{mg} /$ dl 2-hours after oral administration of 75 grams glucose (associating glycated haemoglobin of $5.7 \%$, normal values between 4.5 and 5.9\%).

\section{Endocrine panel}

Normal thyroid function was routinely assessed. Specific adrenal profile showed the following results: negative profile for medullar secretion of catecholamines, normal morning plasma cortisol and ACTH (AdrenoCorticotropic Hormone) with suppression after $1 \mathrm{mg}$ dexamethasone test to $2.06 \mu \mathrm{g} / \mathrm{dl}$ (normal level of suppression is considered at less than $1.8 \mu \mathrm{g} / \mathrm{dl}$ ) (Table 1 ).

TABLE 1. The adrenal profile on a 65-year old female with left adrenal tumour

\begin{tabular}{|l|c|c|c|}
\hline Parameter & value & normal & Units \\
\hline ACTH & 19.04 & $3-66$ & $\mathrm{pg} / \mathrm{ml}$ \\
\hline Morning plasma cortisol & 10.89 & $4.82-19.5$ & $\mu \mathrm{g} / \mathrm{dl}$ \\
\hline Chromogranin A & 21.8 & $20-100$ & $\mathrm{ng} / \mathrm{ml}$ \\
\hline Neuronal specific enolase & 8.48 & $0-12$ & $\mathrm{ng} / \mathrm{ml}$ \\
\hline Plasma metanephrines & 10.1 & $10-90$ & $\mathrm{pg} / \mathrm{ml}$ \\
\hline $\begin{array}{l}\text { Plasma } \\
\text { normetanephrines }\end{array}$ & 88.3 & $20-200$ & $\mathrm{pg} / \mathrm{ml}$ \\
\hline DHEA-S* & 44.84 & $9.4-246$ & $\mu \mathrm{g} / \mathrm{dl}$ \\
\hline
\end{tabular}

*DHEA-S = Dehydroepiandrosterone sulphate

Based on these the tumour was considered negative for a secretory adrenal profile.

\section{Approach}

A secondary imagery approach was done using computed tomography. This confirmed the finding from abdominal ultrasound: a left adrenal mass of 1.7 by $2 \mathrm{~cm}$ (Fig. 3 ).

Periodic check-up is recommended using ultrasound or computed tomography/magnetic resonance imagery. Also, in addition to prior diagnosis of osteoporosis, a central DXA (Dual-Energy X-Ray Absoptiometry) was done and confirmed it based on lumbar L1-2 T-score of -2.6 SD (a bone mineral density of $0.849 \mathrm{~g} / \mathrm{sqcm})$. The patient had normal PTH of $51.78 \mathrm{pg} / \mathrm{ml}$ (normal 16-65 pg/ml), and blood bone turnover markers - of formation P1NP 
$46.72 \mathrm{pg} / \mathrm{ml}$ (normal between 15 and $74 \mathrm{pg} / \mathrm{ml}$ ), and of resorption CrossLaps $0.464 \mathrm{ng} / \mathrm{ml}$ (normal between 0.33 and $0.782 \mathrm{ng} / \mathrm{ml}$ ). Further weekly alendronate and vitamin $D$ supplements were offered to the patient.

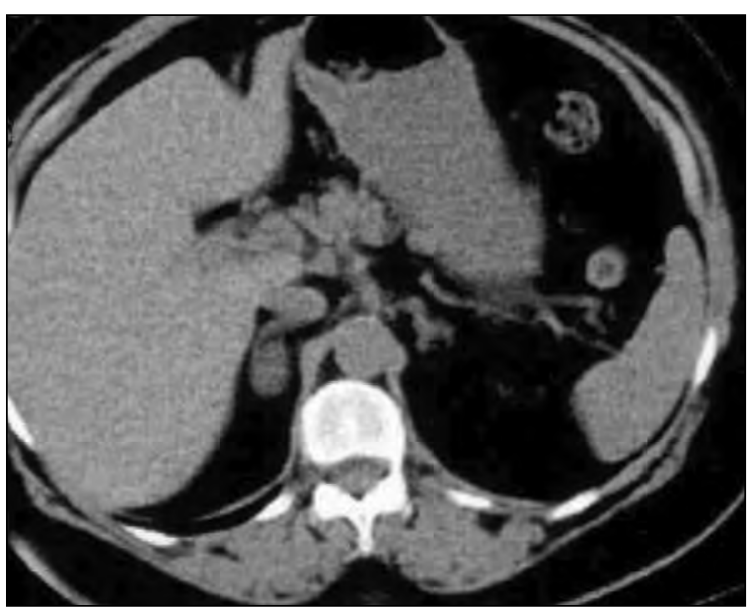

FIGURE 3. Abdominal computed tomography showing a well shaped homogenous tumour at the level of left adrenal gland of 1.7 by $2 \mathrm{~cm}$

\section{DISCUSSION}

The detection of an adrenal tumour based on ultrasound depends on real time examination pa- rameters and the diameters of the mass $[9,10]$. Our patient did not have the diagnosis established 3 years before the current evaluation; it is difficult to appreciate if the tumour was positive at that time knowing the age-related incidence. When it comes to growth rate, this is most probably a slow speed parameter so a dramatic increase of an adrenal incidentaloma is hardly expected $[9,10]$. Another observation is related to the response after dexamethasone suppression test that was near the recommended cut-off, a formerly called subclinical Cushing's syndrome $[2,6]$. There is a current debate if the patients in this particular situation should have adrenalectomy but a conservative approach seemed more adequate in our case with medication control of blood pressure and potential bone loss $[2,6]$.

\section{CONCLUSION}

The use of ultrasound on adrenal masses is related to their detection and follow-up in cases when surgery is not necessary.
Conflict of interest: none declared Financial support: none declared

\section{REFERENCES}

1. Lee JM, Kim MK, Ko SH, Koh JM, Park J, Shong YK et al. Korean Endocrine Society, Committee for Clinical Practice Guidelines. Clinical Guidelines for the Management of Adrenal Incidentaloma. Endocrinol Metab (Seoul) 2017, 32(2), pp. 200-218.

2. Fassnacht M, Arlt W, Bancos I, Dralle $H$, Newell-Price J, Sahdev A, Tabarin A, Terzolo M, Tsagarakis S, Dekkers OM. Management of adrenal incidentalomas: European Society of Endocrinology Clinical Practice Guideline in collaboration with the European Network for the Study of Adrenal Tumors. Eur J Endocrinol 2016, 175(2), pp. G1-G34.

3. Cyrańska-Chyrek E, Grzymisławska M, Ruchała M. Diagnostic pitfalls of adrenal incidentaloma. Endokrynol Pol 2017, 68(3), pp. 360-377.
4. Espiard S, Benomar K, Loyer C, Vahé C, Vantyghem MC. European recommendations for the management of adrenal incidentalomas: A debate on patients follow-up. Ann Endocrinol (Paris) 2018, 79(1), pp. 45-48.

5. Sahdev A. Recommendations for the management of adrenal incidentalomas: What is pertinent for radiologists? $\mathrm{Br} \mathrm{J}$ Radiol 2017, 90(1072), pp. 20160627.

6. Gheorghisan-Galateanu, AA, Carsote, M, Valea, A. Incidentaloma: from general practice to specific endocrine frame. J Pak Med Assoc 2017, 67(6), pp. 917-922.

7. Akkuş G, Evran M, Sert M, Ok F, Tetiker T. Multidisciplinary approach for patients with functional and non-functional adrenal masses and review of the literature. Health Sci Rep 2018, 1(3), pp. e22.
8. Mendiratta-Lala M, Avram A, Turcu AF, Dunnick NR. Adrenal Imaging. Endocrinol Metab Clin North Am 2017, 46(3), pp. 741-759.

9. Farrugia FA, Martikos G, Surgeon C, Tzanetis P, Misiakos E, Zavras N, Charalampopoulos A. Radiology of the adrenal incidentalomas. Review of the literature. Endocr Regul 2017, 51(1), pp. 35-51.

10. Bada M, Castellan, P, Tamburro, FR, Berardinelli, F, Neri, F, Cindolo, L, Schips L. Work up of incidental adrenal mass: State of the art. Urologia 2016, 83(4), pp. 179-185. 